\title{
Recombinant human soluble thrombomodulin prevents acute lung injury in a rat cardiopulmonary bypass model
}

\author{
Shingo Hirao, MD, Kenji Minakata, MD, PhD, Hidetoshi Masumoto, MD, PhD, \\ Kazuhiro Yamazaki, MD, PhD, Tadashi Ikeda, MD, PhD, Kenji Minatoya, MD, PhD, and \\ Ryuzo Sakata, MD, PhD
}

\begin{abstract}
Background: Cardiopulmonary bypass (CPB) may induce systemic inflammatory responses causing acute lung injury. Recombinant human soluble thrombomodulin (rTM) is reported to attenuate the secretion of inflammatory cytokines and the high-mobility group box 1 (HMGB1) protein, which is critical in controlling systemic inflammation and apoptosis. We investigated the protective effects of rTM on CPB-induced lung injury in a rat model.
\end{abstract}

Methods: Eighteen male Sprague-Dawley rats were divided into 3 groups: sham, control (CPB alone), and rTM (CPB + rTM). CPB was conducted in the control group and the rTM group. A bolus of rTM $(3 \mathrm{mg} / \mathrm{kg})$ was administered to the rTM group rats before $\mathrm{CPB}$ establishment.

Results: The ratio of partial pressure of arterial oxygen to the fraction of inspired oxygen only dropped markedly from before CPB in the control group $(P<.001)$. Serum tumor necrosis factor $\alpha$, interleukin (IL) 6 , and HMGB1 levels were significantly higher in the control group after CPB. Pathologic study revealed significantly more severe congestion, alveolar hemorrhage, neutrophil accumulation, and edema, and the number of lung cells expressing HMGB1 increased in the control group. The mRNA expression levels of tumor necrosis factor $\alpha$, IL-6, IL-1 $\beta$, and HMGB1 in the control group were significantly higher than those in other groups. According to Western blot analysis, nuclear factor $-\kappa \mathrm{B}$ p65 in lung tissue was significantly downregulated in the rTM group. The number of apoptotic cells and the protein of cleaved Caspase- 3 were reduced in the rTM group.

Conclusions: These results suggest that rTM prevents acute lung injury through attenuating inflammation and apoptosis during and after CPB in a rat model. (J Thorac Cardiovasc Surg 2017;154:1973-83)

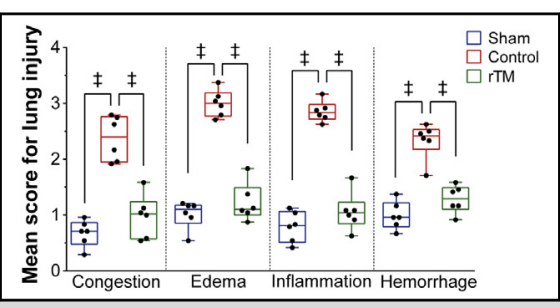

Attenuated lung injury after recombinant human soluble thrombomodulin treatment on a rat cardiopulmonary bypass model.

Central Message

Administration of recombinant human soluble thrombomodulin prevents cardiopulmonary bypass-related acute lung injury through attenuating inflammation and apoptosis.

\section{Perspective}

Administration of recombinant human soluble thrombomodulin may have protective effects on acute lung injury through inhibition of inflammation and apoptosis during and after cardiopulmonary bypass. It would be a novel prophylactic strategy to prevent cardiopulmonary bypass-related lung injury, which can be a lethal complication after cardiovascular surgery.

See Editorial Commentary page 1984.
Acute lung injury (ALI) induced by cardiopulmonary bypass (CPB), a common and serious complication in patients undergoing cardiac surgery with $\mathrm{CPB}$, is an important factor influencing morbidity and mortality

\footnotetext{
From the Department of Cardiovascular Surgery, Graduate School of Medicine, Kyoto University, Kyoto, Japan.

This work was supported by research grants (15H04938) from the Japanese Ministry of Education, Culture, Sports, Science, and Technology (to K.M.).

Received for publication Feb 24, 2017; revisions received April 20, 2017; accepted for publication May 12, 2017; available ahead of print June 20, 2017

Address for reprints: Hidetoshi Masumoto, MD, PhD, Department of Cardiovascular

Surgery, Kyoto University Graduate School of Medicine, 54 Kawahara-cho, Shougoin, Sakyo-ku, Kyoto 606-8507, Japan (E-mail: masumoto@ kuhp.kyoto-u.ac.jp). $0022-5223 / \$ 36.00$

Copyright (c) 2017 by The American Association for Thoracic Surgery http://dx.doi.org/10.1016/j.jtcvs.2017.05.051
}

after surgery and is caused by the activation of several cellular immune systems from contact activation, ischemia-reperfusion injury, and endotoxemia. ${ }^{1}$ Acute respiratory distress syndrome (ARDS) is a rare but serious complication associated with significant mortality. The incidence and mortality of ARDS in patients undergoing CPB were reported to be $0.4 \%$ to $0.6 \%$ and $15 \%$ to $41.5 \%$, respectively. ${ }^{2,3}$ Although various methods have

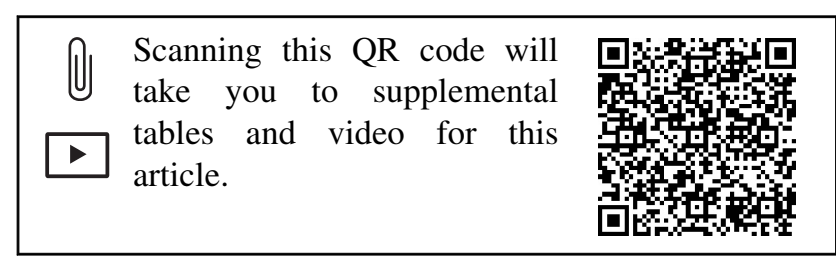




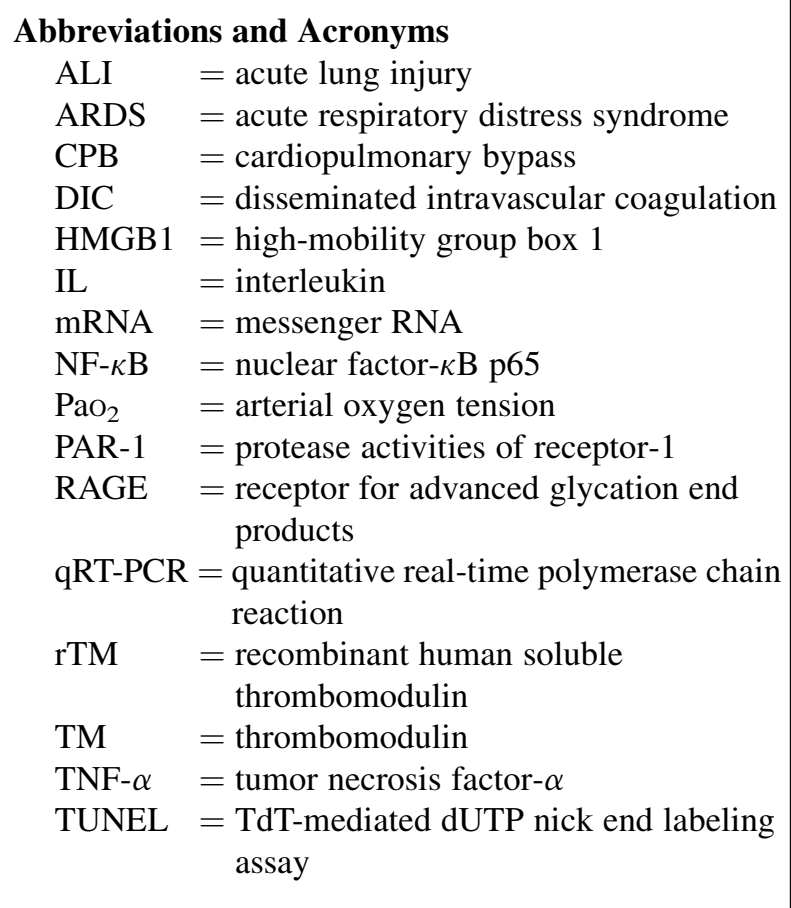

been proposed to protect organs from impaired situations, such as leukocyte-depleting filters ${ }^{4}$; monoclonal anticytokine antibodies ${ }^{5}$; and pharmacologic manipulations by corticosteroids, polymorphonuclear elastase inhibitors, or statins, ${ }^{6}$ only a few modalities are currently used in practice.

High-mobility group box 1 (HMGB1), known as a danger-associated molecular pattern signal, acts as an important structural component in the chromatin complex to regulate gene transcription and to stabilize nucleosome formation. ${ }^{7}$ Once released from damaged cells, HMGB1 binds to the endothelial cell surface receptor, such as the receptor for advanced glycation end products (RAGE) or toll-like receptors, to trigger the activation of the downstream proinflammatory pathway and tissue damage. ${ }^{8}$ Furthermore, HMGB1 is reported to be a biomarker for predicting mortality in patients with ARDS, ${ }^{9}$ and it plays a key role as a late-phase mediator during or after $\mathrm{CPB} .{ }^{10}$ To prevent lung injury, HMGB1 has been a crucial therapeutic target, with treatments, including administration of anti-HMGB1 antibodies or HMGB1 antagonists and hemoperfusion, to eliminate HMGB1 from systemic blood circulation. ${ }^{11,12}$ However, these treatments are not in clinical use as standardized therapeutic options.

Thrombomodulin (TM) is a thrombin-binding anticoagulant cofactor that is expressed on the surface of endothelial cells. ${ }^{13} \mathrm{TM}$ has unique anti-inflammatory properties in its $\mathrm{N}$-terminal lectin-like domain through binding HMGB1 and promoting its degradation. ${ }^{14}$ Another domain of TM activates cytoprotective or antiapoptotic proteins mediated by protease activities of receptor-1 (PAR-1) and the endothelial protein $\mathrm{C}$ receptor. ${ }^{15}$ Recombinant human soluble TM (rTM) is composed of the extracellular domain of TM and has been approved as a medication for patients with disseminated intravascular coagulation (DIC) in Japan. ${ }^{16}$ An international multicenter randomized, doubleblind, placebo-controlled phase IIb study evaluated the safety and efficacy of rTM in patients with sepsis and suspected $\mathrm{DIC},{ }^{17}$ and an international prospective randomized phase III trial is ongoing (ClinicalTrials.gov identifier: NCT01598831). The anti-inflammatory and antiapoptotic effects of rTM have been reported in several experimental models, especially in lung injury models. ${ }^{18,19}$ We hypothesized that the administration of rTM would attenuate systemic inflammation, apoptosis, and lung injury induced by $\mathrm{CPB}$. The aim of this study was to evaluate the protective effects of rTM on ALI induced by CPB in a rat model.

\section{METHODS \\ Animals}

Eighteen male Sprague-Dawley rats (aged 11 weeks, 368-407 g body weight; CLEA Japan Inc, Tokyo, Japan) were used in this study. Before experimentation, all rats were given 1 week to acclimate. The animals in this study received humane care in compliance with the Principles of Laboratory Animal Care formulated by the National Society for Medical Research and the Guide for the Care and Use of Laboratory Animals prepared by the Institute of Laboratory Animal Resources and published by the National Institute of Health (www.nap.edu/catalog/5140.html).

\section{rTM}

rTM was generously provided by Asahi Kasei Pharma Co (Tokyo, Japan) and diluted with saline to a final concentration of $4.0 \mathrm{mg} / \mathrm{mL}$ before experiments.

\section{Experiment Protocols}

The rats were randomly assigned to 1 of the following 3 experimental groups ( $\mathrm{n}=6$ for each group): sham group, control group of rats undergoing $\mathrm{CPB}$, or rTM group of rats undergoing $\mathrm{CPB}$ that received a bolus of rTM $(3 \mathrm{mg} / \mathrm{kg}$ ) via the femoral vein 30 minutes before CPB (Figure 1, $A$ ).

\section{Surgical Procedure}

Each animal was initially anesthetized with 3.0\% isoflurane-mixed air inhalation with a vaporizer. After the insertion of a 16-gauge cannula into the trachea, mechanical ventilation was performed during the entire experiment with $8 \mathrm{~mL} / \mathrm{kg}$ tidal volume, a respiratory rate of 70 cycles per minute, and $30 \%$ of inspired oxygen fraction. Anesthesia was maintained with $1.5 \%$ to $2.0 \%$ isoflurane with an additional administration of $30 \mathrm{mg} / \mathrm{kg}$ intraperitoneal pentobarbital at CPB initiation. All subsequent procedures were performed under aseptic conditions.

$\mathrm{CPB}$ was performed using a surgical technique as previously described in our laboratory with some modifications (Video 1). ${ }^{20,21}$ The right femoral artery was cannulated with a 24-gauge intravenous catheter (SURFLO ETFE I.V. Catheter; Terumo, Tokyo, Japan) to monitor systemic arterial pressure and to analyze arterial blood gas (epoc Blood Analysis System; Alere Medical Co, Tokyo, Japan). After systemic administration of heparin sodium $(500 \mathrm{IU} / \mathrm{kg})$, the left femoral artery was cannulated with a 24-gauge intravenous catheter as an arterial infusion line for the CPB circuit. A 17gauge multiorifice angiocatheter (Happy Cath 19-gauge inner diameter; Medikit Co, Tokyo, Japan) was introduced into the right internal jugular 

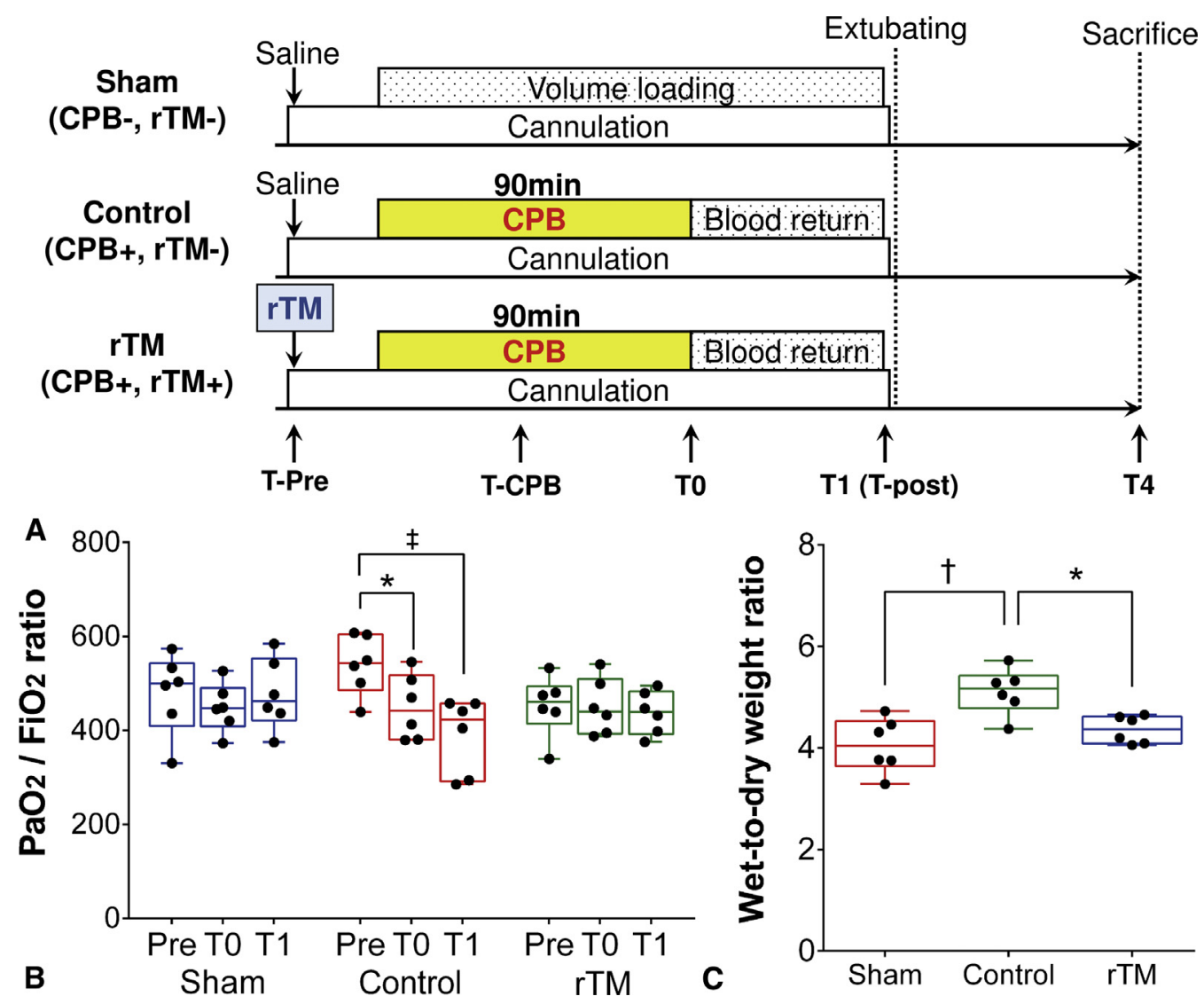

FIGURE 1. Study protocol and effect of recombinant thrombomodulin $(r T M)$ for oxygenation. A, Study protocol. B, The ratio of partial pressure of arterial oxygen $\left(\mathrm{PaO}_{2}\right)$ to the fraction of inspired oxygen $\left(\mathrm{FIO}_{2}\right)$ after cardiopulmonary bypass $(\mathrm{CPB})$ compared with the baseline. $* P<.05$. $\ddagger P<.001$ vs Pre-CPB. C, Wet to dry weight ratio of the lung. The horizontal lines show the 5-number summary, which includes the sample minimum, the lower quartile, the median, the upper quartile, and the sample maximum in the box and whiskers graphs. $* P<.05 . \dagger P<.01$ vs control group. T-Pre, Time before CPB; $T$-CPB, time when undergoing cardiopulmonary bypass; $T$, time for sampling arterial blood; $T$-Post, 1 hour after $\mathrm{CPB} ; T 4$, sacrifice and assessment at $4 \mathrm{~h}$ after $\mathrm{CPB}$.

vein and advanced into the right atrium and inferior vena cava. The CPB circuit was primed with approximately $11 \mathrm{~mL}$ of hydroxyethyl starch solution with $0.2 \mathrm{~mL}$ heparin and $0.5 \mathrm{~mL} 7 \%$ sodium bicarbonate solution (Hespander; Fresenius Kabi Japan, Tokyo, Japan). Blood was pumped from a venous reservoir through a modified neonatal membrane oxygenator (MERA, Tokyo, Japan) using a tubing roller pump (model RP-VT; Furue Science Co, Tokyo, Japan).

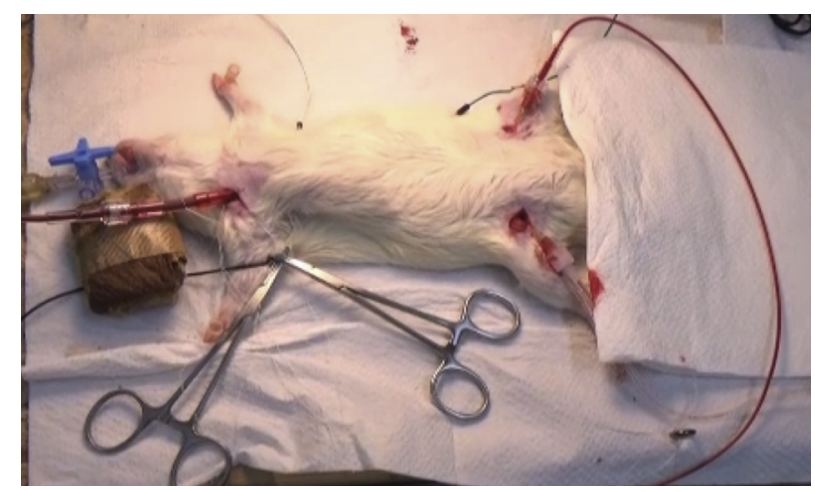

VIDEO 1. Surgical procedure of the rat cardiopulmonary bypass model. Video available at: http://www.jtcvsonline.org/article/S0022-5223(17) 31096-6/addons.
Normothermic CPB with a flow of $100 \mathrm{~mL} / \mathrm{kg} / \mathrm{min}$ was performed for 90 minutes. Furthermore, the TM group rats received a bolus of recombinant $\mathrm{TM}(3 \mathrm{mg} / \mathrm{kg})$ via the femoral vein at 30 minutes before CPB establishment. CPB was terminated after 90 minutes without using any vasoactive agents, and the animals were ventilated for another 60 minutes. The remaining priming solution was gradually infused maintaining the mean arterial pressure at more than $70 \mathrm{~mm} \mathrm{Hg}$. In the sham group, the animals were cannulated and gradually infused with $11 \mathrm{~mL}$ CPB priming solution without conduction of CPB.

Arterial blood samples were collected just before $\mathrm{CPB}, 15$ minutes after CPB initiation, immediately after, and 1 hour after the end of CPB. Hematocrit, hemoglobin concentration, $\mathrm{pH}$, serum lactate, base excess, and partial pressure of arterial oxygen $\left(\mathrm{PaO}_{2}\right)$ and partial pressure of arterial carbon dioxide were measured. Systemic arterial pressure was monitored continually during the experiments, and mean arterial pressure and heart rate were recorded. Rectal temperature was continuously monitored and maintained at $37^{\circ} \mathrm{C}$ by an electric mattress pad and a heat lamp placed over the animal and the $\mathrm{CPB}$ equipment. Four hours after the termination of CPB, all rats were euthanized under anesthesia. The lungs were collected bilaterally and divided into several parts.

\section{Ratio of Partial Pressure of Arterial Oxygen to Fraction of Inspired Oxygen (PF Ratio)}

$\mathrm{PF}$ ratio was calculated using the collected arterial blood samples before $\mathrm{CPB}$, immediately after, and 1 hour after the end of CPB. 


\section{Measurement of Wet to Dry Weight Ratio of the Lung}

The water content of the lung, representing the severity of pulmonary edema, was measured by calculating the wet to dry weight ratio of lung tissues. $^{22}$ The left upper lung was weighed and dried on a heating device at $75^{\circ} \mathrm{C}$ for 72 hours to obtain the pulmonary ratio of wet to dry weight.

\section{Measurement of Cytokines and HMGB1 Concentration}

Fifteen minutes after CPB termination, blood samples were collected and centrifuged at $3000 \mathrm{rpm}$ for 20 minutes at $4^{\circ} \mathrm{C}$ and the serum was obtained. Concentrations of interleukin (IL) 6, tumor necrosis factor $\alpha$ (TNF- $\alpha$ ), and HMGB 1 were assayed by the enzyme-linked immunosorbent assay sandwich method. Serum levels of IL-6 (R\&D Systems Inc, Minneapolis, Minn), TNF- $\alpha$ (R\&D Systems Inc), and HMGB1 (ShinoTest Corporation, Tokyo, Japan) were measured using a commercial enzyme-linked immunosorbent assay kit according to the manufacturer's protocols. The values of absorbance were measured with a microplate reader (Bio-Rad Laboratories Inc, Hercules, Calif) at $450 \mathrm{~nm}$ for HMGB1 or at $450 \mathrm{~nm}$ with a subtract reading at $540 \mathrm{~nm}$ for IL-6 and TNF- $\alpha$.

\section{Histologic Analysis}

The lungs were obtained from animals 4 hours after CPB, fixed in $4 \%$ phosphate-buffered paraformaldehyde, embedded in paraffin, cut into $4-\mu \mathrm{m}$ sections, and then stained with hematoxylin and eosin. Images were photographed using an all-in-one digital microscope (BIOREVO BZ-9000; Keyence, Osaka, Japan) and assessed using the BZ-X Analyzer (Keyence) software. The extent of lung injury was evaluated by a previously described technique. ${ }^{18}$ Twenty-four areas of lung tissue were graded in a blinded manner on a scale of 0 to $4(0=$ abnormalities absent and tissue seems normal, $1=$ light, $2=$ moderate, $3=$ strong, and $4=$ intense) for the degree of congestion, edema, inflammation, and hemorrhage. Then, a mean score for each parameter was calculated.

\section{Immunohistochemical Staining}

Immunohistochemical staining was performed on paraffin-embedded sections with an antibody specific for HMGB1 (Abcam, ab18256) and cleaved Caspase-3 (Cell Signaling Technology, Asp175). Deparaffinized sections were incubated overnight at $4{ }^{\circ} \mathrm{C}$ with a primary antibody for HMGB1 (1:3000) and cleaved Caspase-3 (1:400). Subsequently, sections were incubated at room temperature for 45 minutes in a solution with an antirabbit immunoglobulin G secondary antibody (Nichirei, Tokyo, Japan). The sections were stained with horseradish peroxidase and visualized with diaminobenzidine. After development, sections were counterstained with Mayer's hematoxylin and mounted. The numbers of cells staining positive for HMGB1 and cleaved Caspase-3 were calculated as the number of positive cells in a blinded manner from 10 randomly selected views in each specimen.

\section{TdT-mediated dUTP Nick End Labeling Assay}

Detection of apoptosis in the lung was performed using the TdT-mediated dUTP nick end labeling assay (TUNEL) method. Briefly, each lung tissue was fixed in $4 \%$ phosphate-buffered paraformaldehyde, embedded in paraffin, and cut into $4-\mu \mathrm{m}$ sections. Each selected section was deparaffinized and rehydrated. After incubation with $20 \mu \mathrm{g} / \mathrm{mL}$ proteinase K (Takara Bio Inc, Kusatsu, Japan), endogenous peroxidase was blocked using 3\% hydrogen peroxide in methanol for 5 minutes. TdT enzyme (Takara In Situ Apoptosis Detection Kit; Takara Bio Inc) was dropped on the sections and incubated at $37^{\circ} \mathrm{C}$ for 90 minutes. Then, antifluorescein isothiocyanate horseradish peroxidase conjugate (Takara In Situ Apoptosis Detection Kit; Takara Bio Inc) was dropped on the sections and incubated at $37^{\circ} \mathrm{C}$ for 30 minutes. The sections were stained with horseradish peroxidase and visualized with diaminobenzidine. The sections were then stained with Mayer's hematoxylin for 45 seconds. The number of TUNEL-positive cells was calculated as the number of positive cells in a blinded manner from 10 randomly selected views in each specimen.

\section{Quantitative Real-Time Polymerase Chain Reaction}

The total RNAs were isolated from frozen tissues of the right lung using an RNeasy mini kit (Qiagen, Hilden, Germany). The obtained RNA was reverse-transcribed into complementary DNA using the Invitrogen SuperScript III First-Standard Synthesis SuperMix for Quantitative Real-Time Polymerase Chain Reaction (qRT-PCR) (Life Technologies, Carlsbad, Calif), in accordance with the manufacturer's instructions. The qRT-PCR procedure was performed as follows: $95^{\circ} \mathrm{C}$ for 10 minutes; 40 cycles at $95^{\circ} \mathrm{C}$ for 15 seconds, and $60^{\circ} \mathrm{C}$ for 60 seconds. Levels of messenger RNA (mRNA) were conducted on an Applied Biosystems StepOnePlus Real Time PCR System (ThermoFisher Scientific, Waltham, Mass) by using a Thunderbird Sybr qPCR Mix (TOYOBO, Osaka, Japan). Expression levels for each mRNA were normalized to the mRNA level of the housekeeping gene glyceraldehyde 3-phosphate dehydrogenase. The relative mRNA expression level was calculated using the comparative threshold cycle method. Specific primers were designed as shown in Table E1.

\section{Western Blotting}

The frozen samples of the right lungs were homogenized with Halt Protease Inhibitor Single-Use Cocktail (ThermoFisher Scientific), and the supernatant was collected after centrifuging. For Western blot, $12 \mu \mathrm{g}$ total proteins were subjected to between $4 \%$ and $12 \%$ polyacrylamide gel electrophoresis (NuPAGE Novex Bis-Tris Gel; ThermoFisher Scientific) and transferred onto polyvinylidene difluoride membranes by the iBlot 2 Dry Blotting System (ThermoFisher Scientific). Membranes were incubated with the following primary antibodies: antinuclear factor $\kappa$ B p65 (NF- $\kappa$ B p65) (Cell Signaling Technology, Beverly, Mass) and anticleaved Caspase-3 (Cell Signaling Technology). The membranes were also incubated with horseradish peroxidase-labeled secondary antibodies (1:1000; Cell Signaling Technology) by the automated western processing device iBind Western System (ThermoFisher Scientific). The membranes were then incubated with the ECL Select Western Blotting Detection Reagent (GE Healthcare, Buckinghamshire, United Kingdom). The infrared fluorescence image was obtained using the ImageQuant LAS 500 (GE Healthcare), and the intensity of bands was quantified by ImageQuant TL software (GE Healthcare). After stripping, each membrane was incubated by antiglyceraldehyde 3-phosphate dehydrogenase (1:1000; Cell Signaling Technology) for normalization.

\section{Statistical Analysis}

The values are presented as mean \pm standard deviation. Physiologic variables and ratios of $\mathrm{PaO}_{2}$ to inspired oxygen fraction were assessed for any time and group effect by a 2 -way analysis of variance for main and interaction effects. Other multiple comparisons between groups were performed by one-way analysis of variance followed by Tukey post-hoc test. The results of Western blotting were analyzed by unpaired Student $t$ test. Statistical analyses were performed with GraphPad Prism version 6.0 software (GraphPad Software, Inc, San Diego, Calif).

\section{RESULTS}

\section{Physiologic Data During and After CPB}

All rats survived during the $\mathrm{CPB}$ procedures and for 4 hours after the operation. The physiological data during the operation are summarized in Table 1 and Table E2. The preoperative data were comparable in the 3 groups. 
TABLE 1. Physiologic variables and blood gas analyses during cardiopulmonary bypass

\begin{tabular}{|c|c|c|c|c|c|c|}
\hline Group & Time Point & HR (bpm) & MAP (mm Hg) & RT $\left({ }^{\circ} \mathbf{C}\right)$ & $\mathrm{PaO}_{2}(\mathrm{~mm} \mathrm{Hg})$ & Hemoglobin (g/dL) \\
\hline \multirow[t]{3}{*}{ Sham } & T-Pre & $344 \pm 20$ & $90.7 \pm 5.8$ & $36.3 \pm 0.4$ & $147 \pm 29$ & $12.9 \pm 0.8$ \\
\hline & T-CPB & $362 \pm 16$ & $86.9 \pm 3.3$ & $36.8 \pm 0.3$ & $139 \pm 24$ & $11.9 \pm 0.5$ \\
\hline & T-Post & $352 \pm 24$ & $91.8 \pm 3.8$ & $36.8 \pm 0.2$ & $145 \pm 26$ & $10.8 \pm 0.7$ \\
\hline \multirow[t]{3}{*}{ Control } & T-Pre & $336 \pm 25$ & $92.9 \pm 8.5$ & $36.3 \pm 0.4$ & $164 \pm 19$ & $12.7 \pm 0.9$ \\
\hline & T-CPB & $333 \pm 21$ & $89.9 \pm 9.6$ & $35.8 \pm 0.4^{*}$ & $397 \pm 127 *$ & $7.4 \pm 0.9^{*}$ \\
\hline & T-Post & $362 \pm 24$ & $97.6 \pm 11.2$ & $36.8 \pm 0.4$ & $119 \pm 25$ & $9.7 \pm 1.3$ \\
\hline \multirow[t]{3}{*}{ rTM } & T-Pre & $344 \pm 18$ & $83.8 \pm 7.0$ & $36.7 \pm 0.4$ & $143 \pm 22$ & $13.0 \pm 1.0$ \\
\hline & T-CPB & $341 \pm 19$ & $84.5 \pm 3.1$ & $35.3 \pm 0.2^{*}, \dagger$ & $402 \pm 99^{*}$ & $8.0 \pm 0.7 *$ \\
\hline & T-Post & $349 \pm 26$ & $89.2 \pm 11.9$ & $37.3 \pm 0.5$ & $132 \pm 16$ & $10.2 \pm 1.0$ \\
\hline
\end{tabular}

The physiologic variables of T-CPB are the mean values of 5 points, every 15 minutes when undergoing $\mathrm{CPB}$, and the values of $\mathrm{PaO}_{2}$ and hemoglobin of T-CPB are the mean values of 2 points when undergoing $\mathrm{CPB}$. $H R$, Heart rate; $M A P$, mean arterial pressure; $R T$, rectal temperature; $\mathrm{PaO}_{2}$, partial pressure of arterial oxygen; $T$-Pre, time before $\mathrm{CPB} ; \mathrm{T}-\mathrm{CPB}$, time when undergoing cardiopulmonary bypass; $T$-Post, 1 hour after CPB. $* P<.001$ versus sham. $\dagger P<.05$ versus control.

Throughout the operation, heart rate and mean arterial pressure were stable in all 3 groups. The rectal temperature and hemoglobin level decreased in the control and rTM groups because of hemodilution caused by the priming volume. Conversely, the $\mathrm{PaO}_{2}$ in these groups increased during CPB due to membrane oxygenation. These data indicate successful CPB running through the circuit.

\section{PF Ratio and Wet to Dry Ratio of the Lung}

The PF ratio for each group both at and 1 hour after CPB were compared with the baseline (Figure 1, B). Although the ratio in the control group significantly decreased at and 1 hour after CPB $(539.7 \pm 63.7$ to $449.5 \pm 69.4$ and $390.0 \pm 80.2 ; P=.027$ and $P<.001$, respectively), the ratios in the sham and rTM groups were maintained. The lung wet to dry weight ratio in the control group was significantly higher than those in the sham and rTM groups $(5.11 \pm 0.45$ [control] vs $4.05 \pm 0.54$ [sham], $4.36 \pm 0.27$ [rTM]; $P=.002$ and $P=.023$, respectively) (Figure $1, C$ ). These results indicate that rTM administration rescued pulmonary dysfunction mediated by overhydration during and after CPB.

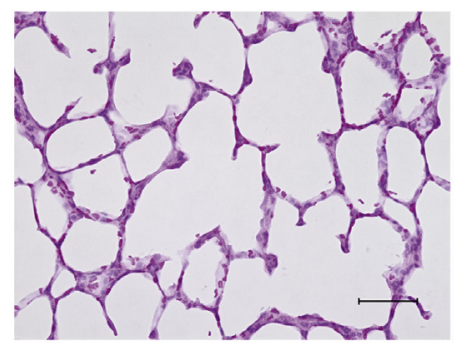

A

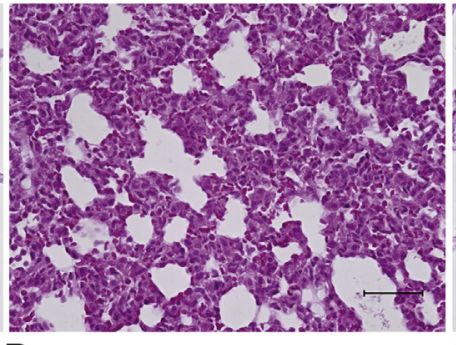

B

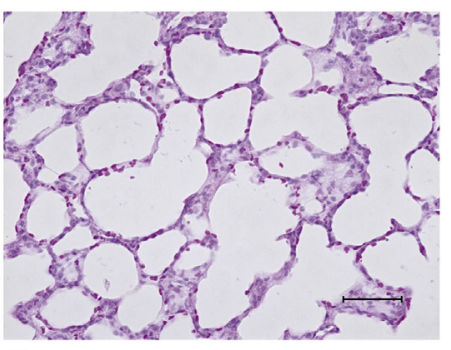

C

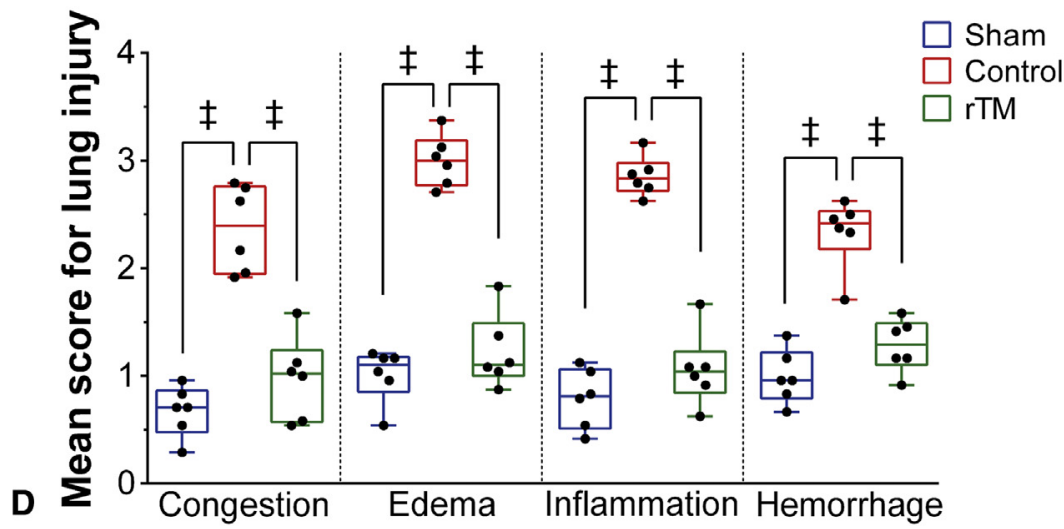

FIGURE 2. Histologic analysis for lungs. A, Representative hematoxylin and eosin staining images in the sham group (sham). B, Representative hematoxylin and eosin staining images in the cardiopulmonary bypass group (control). C, Representative hematoxylin and eosin staining images in the recombinant thrombomodulin group $(r T M)$. D, Histologic analysis for lung injury. The horizontal lines show the 5-number summary, which includes the sample minimum, the lower quartile, the median, the upper quartile, and the sample maximum. Scale bar $=50 \mu \mathrm{m}$. $\ddagger P<.001$. 

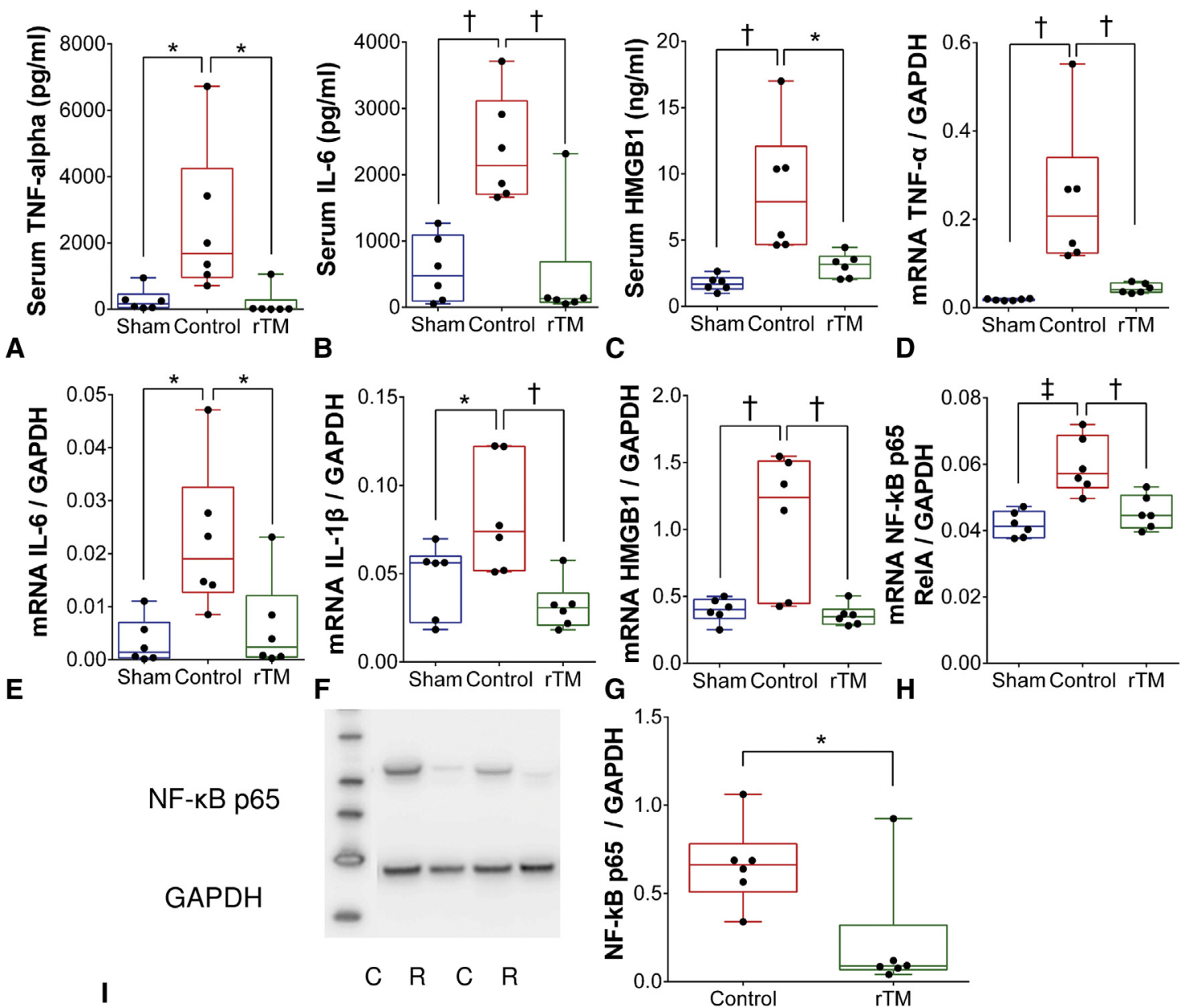

FIGURE 3. Evaluation of inflammatory responses in serum and lung tissue. A, Serum concentration of tumor necrosis factor- $\alpha(T N F-\alpha)$. B, Serum concentration of interleukin-6 (IL-6). C, Serum concentration of high-mobility group box 1 (HMGBI) levels. D, Messenger RNA ( $m R N A$ ) expression levels of TNF- $\alpha$. E, mRNA expression levels of IL-6. F, mRNA expression levels of interleukin-1 $\beta(I L-1 \beta)$. G, mRNA expression levels of HMGB1. H, mRNA expression levels nuclear of factor $-\kappa \mathrm{B}$ p65 RelA (NF- $\kappa$ B p 65 RelA). I, Western blotting for NF- $\kappa \mathrm{B}$ p 65 . The horizontal lines show the 5-number summary, which includes the sample minimum, the lower quartile, the median, the upper quartile, and the sample maximum. $r T M$, Recombinant human soluble thrombomodulin; GAPDH, glyceraldehyde-3-phosphated dehydrogenase; $C$, control; $R$, recombinant thrombomodulin group. $* P<.05$. $\dagger P<.01$. $\ddagger P<.001$ versus control group.

\section{Histologic Analysis of the Lung}

The extent of lung damage in each group assessed by histologic analyses is shown in Figure 2, A-C. For interstitial edema, inflammatory cell infiltration, and hemorrhage, a significant difference was observed in the control group (Figure 2, B). However, the pathologic findings were markedly reduced in the rTM group compared with those in the control group (Figure 2, C). Furthermore, all histologic scoring data were significantly decreased in the rTM group compared with the control group $(0.98 \pm 0.38$ vs $2.37 \pm 0.4$ [congestion], $1.22 \pm 0.34$ vs $3.00 \pm 0.24$ [edema], $1.06 \pm 0.34$ vs $2.85 \pm 0.18$ [inflammation], and $1.29 \pm 0.25$ vs $2.33 \pm 0.32$ [hemorrhage]; $P<.001$ in each parameter) (Figure 2,D), whereas the scores in the rTM group did not differ significantly with those in the sham group $(0.98 \pm 0.38$ vs $0.67 \pm 0.23$ [congestion],
$1.22 \pm 0.34$ vs $1.01 \pm 0.25$ [edema], $1.06 \pm 0.34$ vs $0.99 \pm 0.25$ [inflammation], and $1.29 \pm 0.25$ vs $0.99 \pm 0.25$ [hemorrhage]; $P=.31, .42, .23$, and .19 in each parameter) (Figure 2,D). These results indicate that the rTM administration protected lung tissue from CPBrelated lung damage.

\section{Systemic and Local Lung Inflammatory Responses Associated with HMGB1}

In the present experiment, the serum concentration of TNF- $\alpha$, IL-6, and HMGB1 peaked at the end of CPB. The serum levels of each are shown in Figure 3, A-C. Serum concentrations of TNF- $\alpha$, IL-6, and HMGB1 were significantly higher in the control group than in the sham group $(2542 \pm 2259$ vs $277 \pm 344$ [TNF- $\alpha$ ], $2379 \pm 809$ vs $569 \pm 498$ [IL-6], and $8.76 \pm 4.87$ vs $1.74 \pm 0.58$ 


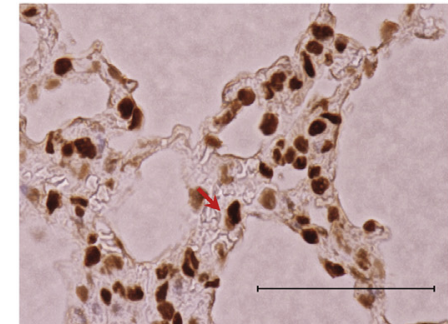

A

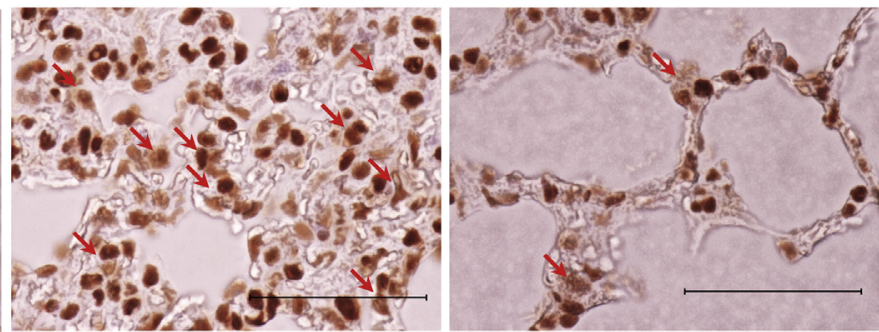

B $\ddagger$

C

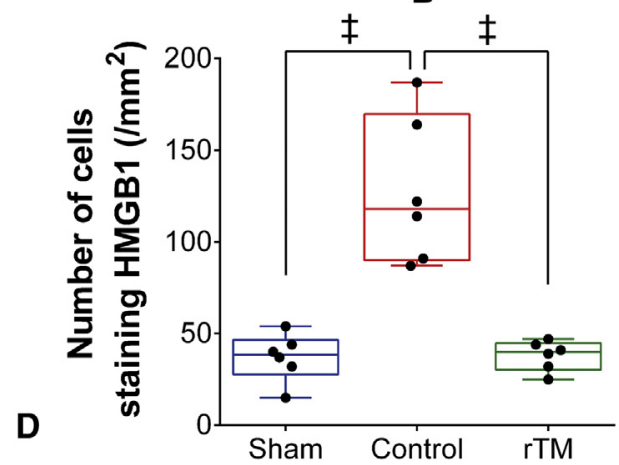

FIGURE 4. High-mobility group box 1 (HMGB1) protein expression in lung tissue. A, Representative immunohistochemical staining images of HMGB1 for lung tissue in the sham group (sham). B, Representative immunohistochemical staining images of HMGB1 for lung tissue in the cardiopulmonary bypass group (control). C, Representative immunohistochemical staining images of HMGB1 for lung tissue in the recombinant thrombomodulin group ( $r T M)$. D, Number of cells staining HMGB1. Scale bar $=50 \mu \mathrm{m}$. Arrows indicate the cells with HMGB1-positive cytoplasm. The horizontal lines show the 5-number summary, which includes the sample minimum, the lower quartile, the median, the upper quartile, and the sample maximum in the box and whiskers graphs. $\ddagger P<.001$ versus control.

[HMGB1]; $P=.027, .002$, and .002 , respectively) and significantly lower in the rTM group than in the control group $(187 \pm 426$ vs $2542 \pm 2259[\mathrm{TNF}-\alpha], 476 \pm 903$ vs $2379 \pm 809$ [IL-6], and $3.09 \pm 0.92$ vs $8.76 \pm 4.87$ [HMGB1]; $P=.002, .021$, and .01 , respectively).

The mRNA expression levels of TNF- $\alpha$, IL- 6 , and IL- $1 \beta$ in the lung were significantly reduced compared with the control group $(0.044 \pm 0.011$ vs $0.247 \pm 0.165$ [TNF- $\alpha$ ], $0.0062 \pm 0.0089$ vs $0.0226 \pm 0.0139$ [IL-6], and $0.032 \pm 0.014$ vs $0.083 \pm 0.032[\mathrm{IL}-1 \beta] ; P=.005, .029$, and .006 , respectively) (Figure 3, $D-F$ ). There was a significant increase in the mRNA expression level of HMGB1 in lung tissue in the control group compared with the sham group (1.07 \pm 0.51 vs $0.40 \pm 0.09 ; P=.004)$ (Figure 3, $G)$. However, mRNA expression of HMGB1 was significantly reduced in the rTM group compared with the control group $(0.36 \pm 0.08$ vs $1.07 \pm 0.51 ; P=.003)$. Immunohistochemical analysis revealed that the number of lung cells expressing cytoplasmic HMGB1 increased only in the control group (Figure 4, $A-C$ ). In contrast, the number of lung cells expressing HMGB1 was dramatically reduced in the rTM group compared with the control group $(38.0 \pm 8.1$ vs $127.5 \pm 40.1 ; P<.001$ ) (Figure $4, D$ ).

The mRNA expression level of NF- $\kappa$ B p65 in the lung was significantly reduced in the rTM group compared with the control group (Figure $3, H)(0.046 \pm 0.005$ vs $0.060 \pm 0.009 ; P=.003)$. Furthermore, concerning the
Western blotting analysis, the protein level of NF- $\kappa \mathrm{B}$ p65 was also significantly reduced in the rTM group compared with the control group $(0.22 \pm 0.34$ vs $0.66 \pm 0.23$; $P=.027$ ) (Figure 3,I). These results indicate that HMGB1 is associated with CPB-related systemic and local lung inflammatory responses, and administration of rTM suppresses the inflammation.

\section{Apoptosis in the Lung}

TUNEL assay for lung tissue is shown in Figure 5, $A-C$. The number of TUNEL-positive cells in the rTM group was significantly less than in the control group ( $43.8 \pm 34.2$ vs $110.7 \pm 59.5 ; P=.037$ ) (Figure 5, G). Additionally, immunohistochemical analysis revealed that the number of lung cells expressing cleaved Caspase-3 increased only in the control group (Figure 5, D-F). In contrast, the number of lung cells expressing cleaved Caspase-3 was dramatically reduced in the rTM group compared with the control group $(208.0 \pm 70.5$ vs $404.0 \pm 113.3 ; P<.001)$ (Figure $5, H$ ). The extent of the mRNA level of Caspase-3 and $\mathrm{Bcl}-2$-associated $\mathrm{X}$ protein was significantly attenuated in the rTM group $(0.012 \pm 0.002$ vs $0.031 \pm 0.007$ [Caspase-3] and $0.075 \pm 0.008$ vs $0.133 \pm 0.028$ [Bcl-2-associated X protein]; $P<.001$ in each case) (Figure 5, $I$ and $J$ ). Likewise, the protein expression of cleaved Caspase-3 on the Western blotting analysis was also suppressed in the rTM group compared with the control 

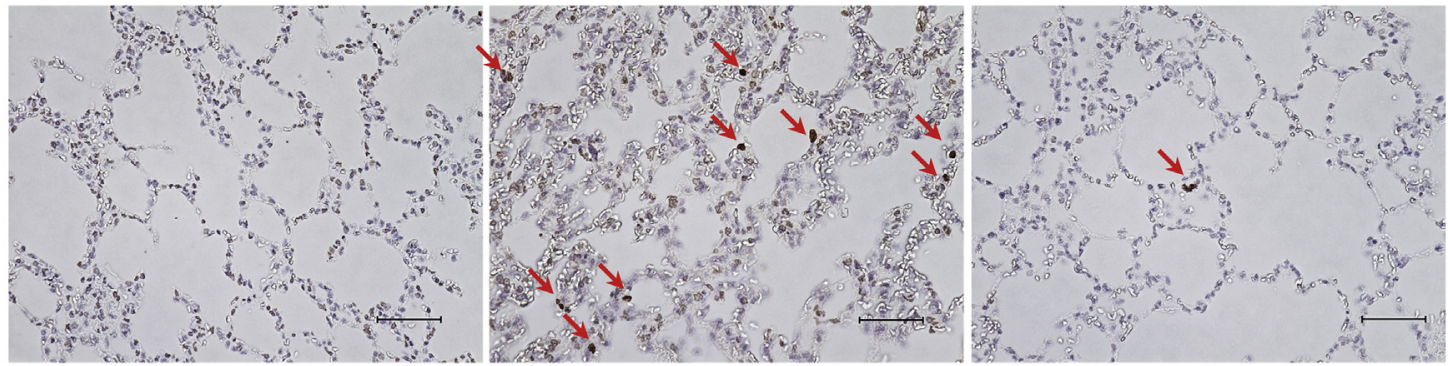

A

B

C
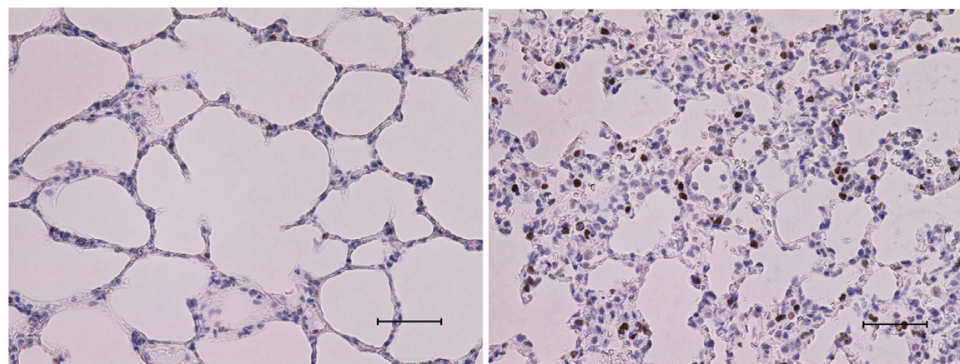

D

E
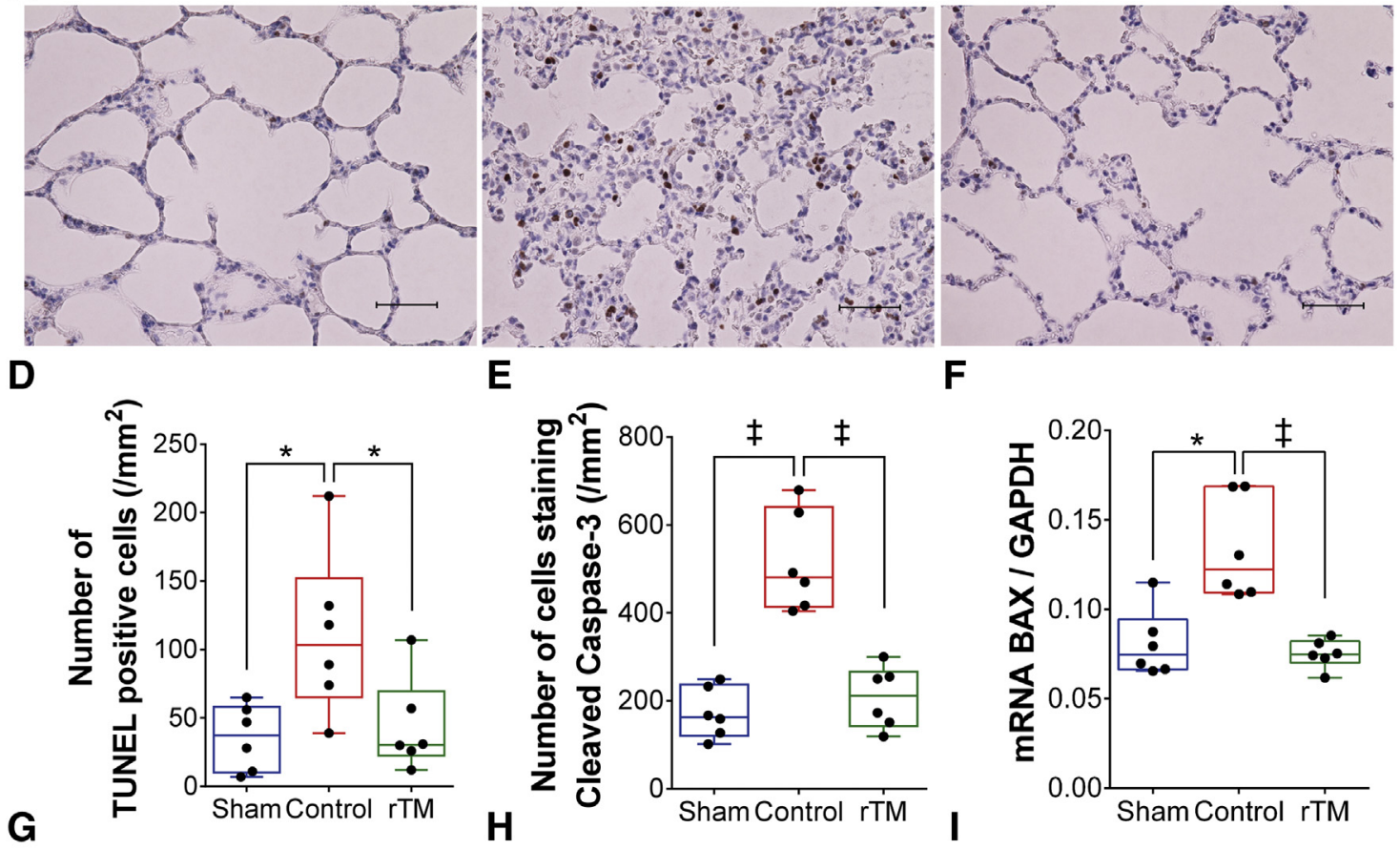

$\mathbf{F}$
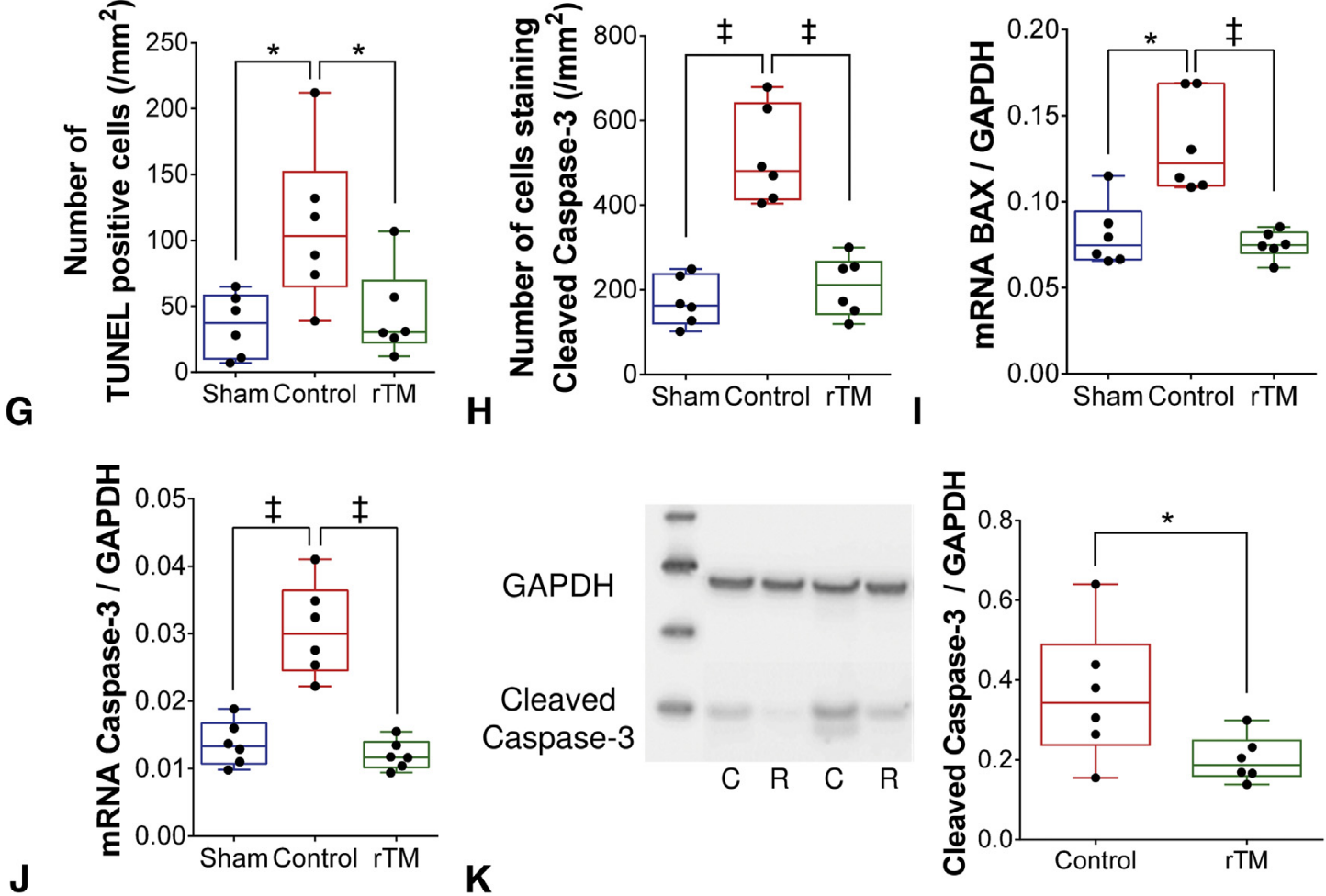

FIGURE 5. Evaluation of apoptotic response in lung tissue. A, Representative terminal deoxynucleotidyl transferase dUTP nick-end labeling (TUNEL) assay images for lung tissue in the sham group (sham). B, Representative TUNEL assay images for lung tissue in the cardiopulmonary bypass group (control). C, Representative TUNEL assay images for lung tissue in the recombinant thrombomodulin group ( $r T M)$. D, Representative images of cleaved Caspase-3 for lung tissue in sham. E, Representative images of cleaved Caspase-3 for lung tissue in control. F, Representative images of cleaved Caspase-3 for lung tissue in rTM. G, Number of TUNEL positive cells (arrow). H, Number of cleave Caspase-3 positive alveolar cells. I, Messenger RNA ( $m R N A$ ) expression levels of Bcl-2-associated X protein (BAX). J, mRNA expression levels of Caspase-3. K, Western blotting of cleaved Caspase-3. The horizontal lines show the 5-number summary, which includes the sample minimum, the lower quartile, the median, the upper quartile, and the sample maximum in the box and whiskers graphs. Scale bar $=50 \mu \mathrm{m}$. GAPDH, Glyceraldehyde- 3 -phosphated dehydrogenase; $C$, control; $R$, rTM. $* P<.05$. $\ddagger P<.001$ versus control. 


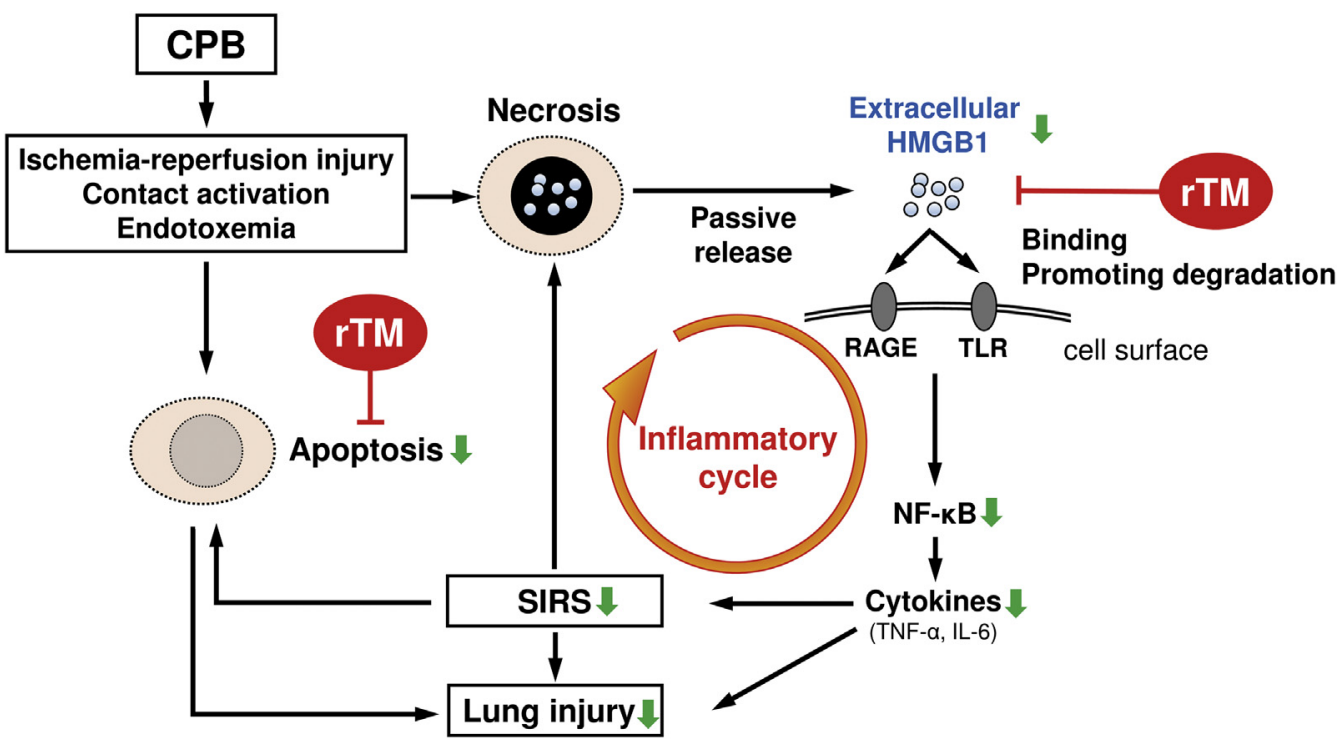

FIGURE 6. Putative mechanisms of recombinant human thrombomodulin $(r T M)$ on cardiopulmonary bypass $(C P B)$-related lung injury in this study. Putative mechanisms for how administration of rTM prevents lung injury induced by CPB. Green arrows indicate tentative effects of rTM administration. $H M G B 1$, High mobility group box $1 ; R A G E$, receptor for glycan end product; $T L R$, toll-like receptor; SIRS, systemic inflammatory response syndrome; $N F-\kappa B$, nuclear factor- $\kappa \mathrm{B} ; T N F-\alpha$, tumor necrosis factor- $\alpha$; $I L-6$, interleukin-6.

group $(0.20 \pm 0.06$ vs $0.36 \pm 0.17 ; P=.027)$ (Figure $5, K)$. These results indicate that rTM administration mitigates apoptosis in the lung mediated by CPB.

\section{DISCUSSION}

In the present study, we tried to determine whether an rTM treatment possesses protective effects on a $\mathrm{CPB}$-induced lung injury. The results demonstrated that the administration of rTM before undergoing CPB was associated with a significant reduction of systemic inflammatory responses and local lung inflammation, which led to protection against lung injury. Our results also suggested that the administration of rTM attenuated systemic HMGB1 concentration and HMGB1 activity in the lung, which might have attenuated exacerbation of inflammatory responses. In addition, rTM attenuated CPB-related apoptosis in the lung.

HMGB1 is an important structural component of the chromatin complex, which shapes the nucleosomal structure and is involved in various processes such as DNA binding, replication, repair and bending, and gene transcription and stability. ${ }^{7,23}$ Under stressed conditions, HMGB 1 can be actively released from immune cells and passively released from necrotic or damaged cells. ${ }^{24}$ Secreted HMGB1 binds to RAGE and/or innate toll-like receptor 2 and 4 and, subsequently, activates signal cascades, which results in further downstream inflammatory cytokine release, establishing a vicious inflammatory cycle. $^{8,25}$ TM binds to HMGB1 by its D1 domain and interferes with the binding of HMGB1 to RAGE, ${ }^{14}$ which results in decreased proinflammatory activity of
HMGB1. TM also plays an important role in the degradation of HMGB $1 .^{26}$ These molecular and biophysical characteristics of TM encouraged us to verify the anti-inflammatory effect of TM against CPB-related inflammatory lung injury, which is potentially related to the activation of HMGB1.

We demonstrated that the administration of rTM dramatically reduced the serum and lung expression levels of HMGB1, inflammatory cytokines, and NF- $\kappa \mathrm{B}$, a key transcription factor regulating the inflammatory response ${ }^{27}$ in our rat CPB model. We analyzed the concentrations of the inflammatory biomarkers within a short period of time from the cessation of CPB based on previous reports indicating that those markers rapidly alleviate after the inflammatory stimulus in rat models, ${ }^{18,28,29}$ and successfully demonstrated the effect of rTM on the attenuation of CPB-related inflammation. Based on previous clinical studies, the serum secretion of HMGB1 level is elevated in patients undergoing cardiac surgery, ${ }^{10,30}$ and a recent clinical study showed that the peak serum HMGB1 level during CPB was associated with more severe systemic inflammatory response syndrome and a higher incidence of lung oxygenation impairment after $\mathrm{CPB} .^{10}$ Additionally, the serum HMGB1 level is an independent biomarker for predicting intensive care unit mortality in patients with severe pneumonia and ARDS. ${ }^{31}$ In the present study, the serum HMGB1 level after 90 minutes of CPB in the control group was comparable with the values in reported clinical studies, ${ }^{10,30}$ indicating that we could successfully simulate severe CPB-related ARDS associated with 
HMGB1 activation in our rat CPB model and show the advantageous effect of TM against the inflammation, which may fairly be relevant in clinical settings.

The pathophysiology of ARDS is characterized by complex mechanisms, including inflammation and apoptosis. ${ }^{32}$ Epithelial cell apoptosis is considered to be fundamentally associated with the pathogenesis of ALI and ARDS in humans. One of the antiapoptotic effects of rTM is mediated by the activation of protein $\mathrm{C}$ and PAR-1 and downregulation of Bcl-2associated $\mathrm{X}$ protein, which stimulates the release of promoters of apoptosis such as cytochrome c and Caspase$3{ }^{33,34}$ Furthermore, suppression of inflammatory cytokines such as TNF- $\alpha$ mitigates the extrinsic apoptotic pathway mediated by cell surface death receptors belonging to the tumor necrosis factor-receptor family, which accelerates cleavage and activation of Caspase- $3 .{ }^{35}$ In the present study, rTM showed an antiapoptotic effect on lung injury, which may potentially be mediated by a direct mechanism through PAR-1 activation and the extrinsic pathway related to suppression of inflammatory cytokines. The proposed mechanism as to how rTM may attenuate the ALI induced by CPB is summarized in Figure 6.

The present study includes several limitations. First, we did not investigate the appropriate dose, dose-dependent effect, and the administration timing of rTM. A previous study administrating the same dose of rTM in a lipopolysaccharide-induced rat lung injury model, ${ }^{18}$ demonstrated the attenuation of lung injury, which allowed us to refer this concentration to our study. However, the situation, extent, and/or timing of the inflammatory change may be different from our study considering the divergence of inflammatory mediators, ${ }^{36}$ and a closer investigation of the appropriate dose is vital before proceeding with clinical trials. Second, we did not investigate the influence or aggregate effects of rTM for surgical bleeding during cardiac surgery using CPB. Nonetheless, a phase III trial using rTM with a low dose of heparin in DIC patients did not increase the incidents of bleeding, ${ }^{37}$ and we should be aware of the risk of surgical bleeding considering the use of TM in combination with a high dose of heparin sodium, which is commonly used for anticoagulation during $\mathrm{CPB}$ in preclinical large-animal experiments. Finally, potential differences in immune systems between humans and rodents, and clinical settings, such as the use of exogenous blood products that influence the extent of hemodilution, have not been examined and should be further investigated.

\section{CONCLUSIONS}

rTM may attenuate ALI through inhibition of systemic and local lung inflammation during and after CPB in a rat model. The present study may provide the key for a novel strategy to prevent lung injury induced by $\mathrm{CPB}$, which should be validated by preclinical and clinical trials.

\section{Conflict of Interest Statement}

Authors have nothing to disclose with regard to commercial support.

The authors thank Dr M. Funamoto for providing technical support, Mr S. Miyake for providing expert technical assistance, and Asahi Kasei Pharma for providing the recombinant human soluble thrombomodulin.

\section{References}

1. Apostolakis E, Filos KS, Koletsis E, Dougenis D. Lung dysfunction following cardiopulmonary bypass. J Card Surg. 2010;25:47-55.

2. Milot J, Perron J, Lacasse Y, Létourneau L, Cartier PC, Maltais F. Incidence and predictors of ARDS after cardiac surgery. Chest. 2001;119:884-8.

3. Kogan A, Preisman S, Levin S, Raanani E, Sternik L. Adult respiratory distress syndrome following cardiac surgery. J Card Surg. 2014;29:41-6.

4. Ilmakunnas M, Pesonen EJ, Ahonen J, Rämö J, Siitonen S, Repo H. Activation of neutrophils and monocytes by a leukocyte-depleting filter used throughout cardiopulmonary bypass. J Thorac Cardiovasc Surg. 2005;129:851-9.

5. Ma XL, Weyrich AS, Lefer DJ, Buerke M, Albertine KH, Kishimoto TK, et al. Monoclonal antibody to L-selectin attenuates neutrophil accumulation and protects ischemic reperfused cat myocardium. Circulation. 1993;88: 649-58.

6. Pierri MD, Crescenzi G, Zingaro C, D'Alfonso A, Capestro F, Scocco V, et al. Prevention of atrial fibrillation and inflammatory response after on-pump coronary artery bypass using different statin dosages: a randomized, controlled trial. Gen Thorac Cardiovasc Surg. 2016;64:395-402.

7. Štros M, Launholt D, Grasser KD. The HMG-box: A versatile protein domain occurring in a wide variety of DNA-binding proteins. Cell Mol Life Sci. 2007; 64:2590-606.

8. Hreggvidsdottir H, Lundberg A. High mobility group box protein 1 (HMGB1)-partner molecule complexes enhance cytokine production by signaling through the partner molecule receptor. Mol Med. 2012;18:1.

9. Abraham E, Arcaroli J, Carmody A, Wang H, Tracey KJ. HMG-1 as a mediator of acute lung inflammation. J Immunol. 2000;165:2950-4.

10. Kohno T, Anzai T, Shimizu H, Kaneko H, Sugano Y, Yamada S, et al. Impact of serum high-mobility group box 1 protein elevation on oxygenation impairment after thoracic aortic aneurysm repair. Heart Vessels. 2011;26:306-12.

11. Hamada N, Maeyama T, Kawaguchi T, Yoshimi M, Fukumoto J, Yamada M, et al. The role of high mobility group box 1 in pulmonary fibrosis. Am J Respir Cell Mol Biol. 2008;39:440-7.

12. Nakamura T, Fujiwara N, Sato E, Kawagoe Y, Ueda Y, Yamada S, et al. Effect of polymyxin B-immobilized fiber hemoperfusion on serum high mobility group box-1 protein levels and oxidative stress in patients with acute respiratory distress syndrome. ASAIO J. 2009;55:395-9.

13. Maruyama I, Bell CE, Majerus PW. Thrombomodulin is found on endothelium of arteries, veins, capillaries, and lymphatics, and on syncytiotrophoblast of human placenta. J Cell Biol. 1985;101:363-71.

14. Abeyama K, Stern DM, Ito Y, Kawahara KI, Yoshimoto Y, Tanaka M, et al. The $\mathrm{N}$-terminal domain of thrombomodulin sequesters high-mobility group-B1 protein, a novel antiinflammatory mechanism. J Clin Invest. 2005;115:1267-74.

15. Griffin JH, Fernández JA, Gale AJ, Mosnier LO. Activated protein C. J Thromb Haemost. 2007;5:73-80.

16. Gomi K, Zushi M, Honda G, Kawahara S, Matsuzaki O, Kanabayashi T, et al. Antithrombotic effect of recombinant human thrombomodulin on thrombin-induced thromboembolism in mice. Blood. 1990;75:1396-9.

17. Vincent J-L, Ramesh MK, Ernest D, LaRosa SP, Pachl J, Aikawa N, et al. A randomized, double-blind, placebo-controlled, Phase $2 \mathrm{~b}$ study to evaluate the safety and efficacy of recombinant human soluble thrombomodulin, ART-123, in patients with sepsis and suspected disseminated intravascular coagulation. Crit Care Med. 2013;41:2069-79.

18. Hagiwara S, Iwasaka H, Matsumoto S, Hasegawa A, Yasuda N, Noguchi T. In vivo and in vitro effects of the anticoagulant, thrombomodulin, on the inflammatory response in rodent models. Shock. 2010;33:282-8.

19. Kudo D, Toyama M, Aoyagi T, Akahori Y, Yamamoto H, Ishii K, et al. Involvement of high mobility group box 1 and the therapeutic effect of recombinant thrombomodulin in a mouse model of severe acute respiratory distress syndrome. Clin Exp Immunol. 2013;173:276-87. 
20. Taki T, Masumoto H, Funamoto M, Minakata K, Yamazaki K, Ikeda T, et al. Fetal mesenchymal stem cells ameliorate acute lung injury in a rat cardiopulmonary bypass model. J Thorac Cardiovasc Surg. 2017;153:726-34.

21. Funamoto M, Masumoto H, Takaori K, Taki T, Setozaki S, Yamazaki K, et al. Green tea polyphenol prevents diabetic rats from acute kidney injury after cardiopulmonary bypass. Ann Thorac Surg. 2016;101:1507-13.

22. Liu Z, Xi R, Zhang Z, Li W, Liu Y, Jin F, et al. 4-Hydroxyphenylacetic acid attenuated inflammation and edema via suppressing HIF-1 $\alpha$ in seawater aspiration-induced lung injury in rats. Int J Mol Sci. 2014;15:12861-84.

23. Stros M. HMGB proteins: interactions with DNA and chromatin. Biochim Biophys Acta. 2010;1799:101-13.

24. Scaffidi P, Misteli T, Bianchi ME. Release of chromatin protein HMGB1 by necrotic cells triggers inflammation. Nature. 2002;418:191-5.

25. Kokkola R, Andersson $\AA$, Mullins G, Östberg T, Treutiger CJ, Arnold B, et al. RAGE is the major receptor for the proinflammatory activity of HMGB1 in rodent macrophages. Scand J Immunol. 2005;61:1-9.

26. Van de Wouwer M, Plaisance S, De Vriese A, Waelkens E, Collen D, Persson J, et al. The lectin-like domain of thrombomodulin interferes with complement activation and protects against arthritis. J Thromb Haemost. 2006;4:1813-24.

27. Valen G, Paulsson G, Vaage J. Induction of inflammatory mediators during reperfusion of the human heart. Ann Thorac Surg. 2001;71:226-32.

28. Liu K, Shen L, Wang J, Dong G, Wu H, Shao H, et al. The preventative role of curcumin on the lung inflammatory response induced by cardiopulmonary bypass in rats. J Surg Res. 2012;174:73-82.

29. Shao H, Shen Y, Liu H, Dong G, Qiang J, Jing H. Simvastatin suppresses lung inflammatory response in a rat cardiopulmonary bypass model. Ann Thorac Surg. 2007;84:2011-8.
30. Zhang Z, Wu Y, Zhao Y, Xiao X, Liu J, Zhou X. Dynamic changes in HMGB1 levels correlate with inflammatory responses during cardiopulmonary bypass. Exp Ther Med. 2013;5:1523-7.

31. Tseng C-C, Fang W-F, Leung S-Y, Chen H-C, Chang Y-C, Wang C-C, et al Impact of serum biomarkers and clinical factors on intensive care unit mortality and 6-month outcome in relatively healthy patients with severe pneumonia and acute respiratory distress syndrome. Dis Markers. 2014;2014:804654.

32. Ware LB, Matthay MA. The acute respiratory distress syndrome. $N$ Engl J Med. 2000;342:1334-49.

33. Ota Y, Kumamoto T, Ishibe A, Watanabe K, Mori R, Taniguchi K, et al Thrombomodulin improves rat survival after extensive hepatectomy. J Surg Res. 2015;194:375-82.

34. Desagher S, Osen-Sand A, Nichols A, Eskes R, Montessuit S, Lauper S, et al Bid-induced conformational changes of Bax is responsible for mitochondrial cytochrome c release during apoptosis. J Cell Biol. 1999;144:891-901.

35. Green DR, Reed JC. Mitochondria and apoptosis. Science. 1998;281:1309-12.

36. Sanchez PG, Pasrija C, Mulligan MJ, Wadhwa M, Pratt DL, Li T, et al. A novel large animal model of acute respiratory distress syndrome induced by mitochondrial products. Ann Surg. October 4, 2016 [Epub ahead of print].

37. Saito H, Maruyama I, Shimazaki S, Yamamoto Y, Aikawa N, Ohno R, et al. Efficacy and safety of recombinant human soluble thrombomodulin (ART-123) in disseminated intravascular coagulation: results of a phase III, randomized, double-blind clinical trial. J Thromb Haemost. 2007;5:31-41.

Key Words: thrombomodulin, cardiopulmonary bypass, systemic inflammation, acute lung injury, apoptosis 
TABLE E1. Sequences of primers used for quantitative real-time polymerase chain reaction (qRT-PCR)

\begin{tabular}{|c|c|c|c|}
\hline \multirow{2}{*}{$\begin{array}{l}\text { Target gene } \\
\text { GAPDH }\end{array}$} & \multicolumn{2}{|c|}{ Oligonucleotide for qRT-PCR primer sequence $5^{\prime}-3^{\prime}$} & \multirow{2}{*}{$\begin{array}{l}\text { GenBank accession } \\
\text { NM_017008 }\end{array}$} \\
\hline & Forward & TATCGGACGCCTGGTTAC & \\
\hline & Reverse & CTGTGCCGTTGAACTTGC & \\
\hline \multirow[t]{2}{*}{ IL-1 $\beta$} & Forward & ATAGCAGCTTTCGACAGTGAGG & NM_031512 \\
\hline & Reverse & GGAGAATACCACTTGTTGGCTTA & \\
\hline \multirow[t]{2}{*}{ IL-6 } & Forward & CAGCCACTGCCTTCCCTACTTC & NM_012589 \\
\hline & Reverse & TAGCCACTCCTTCTGTGACTCTAACT & \\
\hline \multirow[t]{2}{*}{ TNF- $\alpha$} & Forward & CGTCGTAGCAAACCACCAAGC & NM_012675.3 \\
\hline & Reverse & CCAGTCGCCTCACAGAGCAAT & \\
\hline \multirow[t]{2}{*}{ HMGB1 } & Forward & TGCTTTTGCCCATTTTGGGTC & NM_012963 \\
\hline & Reverse & TATGCAGGGTGTGTGGACAA & \\
\hline \multirow[t]{2}{*}{ NF- $\kappa$ B p65/RelA } & Forward & AACAACACAGACCCAGGAGT & NM_199267 \\
\hline & Reverse & CTGTCACCAGGCGAGTTATAG & \\
\hline \multirow[t]{2}{*}{ BAX } & Forward & TGCAGAGGATGATTGCTGAT & NM_017059.2 \\
\hline & Reverse & GATCAGCTCGGGCACTTTAG & \\
\hline \multirow[t]{2}{*}{ Caspase-3 } & Forward & GAGACAGACAGTGGAACTGACGATG & NM_012922 \\
\hline & Reverse & GGCGCAAAGTGACTGGATGA & \\
\hline
\end{tabular}

$\overline{q R T-P C R}$, Quantitative real-time polymerase chain reaction; $G A P D H$, glyceraldehyde-3-phosphated dehydrogenase; $I L$, interleukin; TNF- $\alpha$, tumor necrosis factor $\alpha$; $H M G B 1$, high-mobility group box $1 ; N F-\kappa B$, nuclear factor- $\kappa \mathrm{B} ; B A X$, Bcl-2-associated $\mathrm{X}$ protein.

TABLE E2. Blood gas analyses during cardiopulmonary bypass

\begin{tabular}{|c|c|c|c|c|c|c|c|c|}
\hline Group & Time point & pH & $\begin{array}{c}\mathrm{PaO}_{2} \\
(\mathrm{~mm} \mathrm{Hg})\end{array}$ & $\begin{array}{c}\mathrm{PaCO}_{2} \\
(\mathrm{~mm} \mathrm{Hg})\end{array}$ & $\begin{array}{c}\text { Hemoglobin } \\
\text { (g/dL) }\end{array}$ & $\begin{array}{c}\text { Hematocrit } \\
(\%)\end{array}$ & $\begin{array}{c}\text { Lactate } \\
(\mathrm{mmol} / \mathrm{L})\end{array}$ & $\begin{array}{c}\text { Base excess } \\
(\mathrm{mmol} / \mathrm{L})\end{array}$ \\
\hline \multirow[t]{3}{*}{ Sham } & T-Pre & $7.45 \pm 0.04$ & $147 \pm 29$ & $36.0 \pm 3.5$ & $12.9 \pm 0.8$ & $38.0 \pm 2.2$ & $2.0 \pm 0.3$ & $0.7 \pm 0.6$ \\
\hline & $\mathrm{T}-\mathrm{CPB}$ & $7.43 \pm 0.04$ & $139 \pm 24$ & $38.0 \pm 2.8$ & $11.9 \pm 0.5$ & $34.8 \pm 1.5$ & $3.3 \pm 0.7$ & $1.0 \pm 3.8$ \\
\hline & T-Post & $7.42 \pm 0.03$ & $145 \pm 26$ & $36.0 \pm 3.0$ & $10.8 \pm 0.7$ & $31.8 \pm 1.9$ & $3.5 \pm 1.6$ & $-0.7 \pm 1.5$ \\
\hline \multirow[t]{3}{*}{ Control } & T-Pre & $7.47 \pm 0.02$ & $164 \pm 19$ & $32.7 \pm 2.9$ & $12.7 \pm 0.9$ & $37.3 \pm 2.3$ & $2.4 \pm 0.8$ & $0.3 \pm 1.4$ \\
\hline & T-CPB & $7.53 \pm 0.05 \ddagger$ & $397 \pm 127 \ddagger$ & $29.4 \pm 4.1 \dagger$ & $7.4 \pm 0.9 \ddagger$ & $21.9 \pm 2.5 \ddagger$ & $4.9 \pm 0.7^{*}$ & $1.4 \pm 0.9$ \\
\hline & T-Post & $7.42 \pm 0.06$ & $119 \pm 25$ & $41.3 \pm 5.7$ & $9.7 \pm 1.3$ & $28.7 \pm 3.8$ & $3.3 \pm 1.0$ & $1.7 \pm 1.2^{*}$ \\
\hline \multirow[t]{3}{*}{ rTM } & T-Pre & $7.45 \pm 0.03$ & $143 \pm 22$ & $36.6 \pm 6.1$ & $13.0 \pm 1.0$ & $38.3 \pm 3.0$ & $2.3 \pm 0.6$ & $0.6 \pm 1.0$ \\
\hline & $\mathrm{T}-\mathrm{CPB}$ & $7.56 \pm 0.02 \ddagger$ & $402 \pm 99 \ddagger$ & $28.2 \pm 1.6 \dagger$ & $8.0 \pm 0.7 \ddagger$ & $23.4 \pm 2.2 \ddagger$ & $3.7 \pm 0.9$ & $2.8 \pm 1.6$ \\
\hline & T-Post & $7.41 \pm 0.04$ & $132 \pm 16$ & $43.4 \pm 7.0^{*}$ & $10.2 \pm 1.0$ & $29.8 \pm 3.0$ & $2.1 \pm 0.9^{*}$ & $2.7 \pm 1.5 \dagger$ \\
\hline
\end{tabular}

The values of blood gas analyses of T-CPB are the mean values of 2 points when undergoing CPB. $\mathrm{PaO}_{2}$, Partial pressure of arterial oxygen; $\mathrm{PaCO}_{2}$, partial pressure of arterial carbon dioxide; T-Pre, time before CPB; $T$-CPB, time when undergoing cardiopulmonary bypass; $T$-Post, 1 hour after CPB; $r T M$, recombinant human soluble thrombomodulin. $* P<.05$ versus sham. $\dagger P<.01$ versus sham. $\ddagger P<.001$ versus sham. 